\title{
CLASSICAL OPTIMIZATION OF BAGASSE ASH CONTENT IN CEMENT- STABILIZED LATERITIC SOIL
}

\author{
U. N. Okonkwo ${ }^{1, *}$ and J. C. Agunwamba ${ }^{2}$ \\ 1DEPT OF CiVIL ENGR., MiCHAEL OKPARA UNIVERSITY OF AGRICULTURE UMUdiKE, UMUAHIA, ABIA STATE, NIGERIA. \\ 2DEPARTMENT OF Civil ENGINEERING, UNIVERSITY OF NigERIA, NSUKKA. ENUGU STATE, NIGERIA \\ E-mail addresses: ${ }^{1}$ ugochukwuokonkwo75@gmail.com, 2nwambaagu@yahoo.com
}

\begin{abstract}
Optimization of construction materials with laboratory data is a very possible way of minimizing waste of resources (materials and cost). There had been several successful attempts of optimization of construction materials. However, optimization in soil stabilization for road-work has been very rare because of its complexities. Compaction, California bearing ratio, unconfined compressive strength and durability tests were carried out on cement-stabilized soil. Constant cement contents of $2 \%, 4 \%, 6 \%$ and $8 \%$ with variations of bagasse ash from $0 \%$ to $20 \%$ at 2\% intervals and all percentages used were by the weight of dry soil. The classical method was applied in this work to optimize the amount of bagasse ash content in cement-stabilized lateritic soil. Geometric models that govern the relationships of cost of bagasse ash content, cement content, optimum moisture content and strength characteristics of the stabilized-soil matrix were used to develop non-linear programming model. Then it was linearized and solved using the simplex method with sensitivity analysis. The optimal solution at the desired unconfined compressive strength and California bearing ratio for sub-base of road-work for bagasse ash content, cement content and optimum moisture content were found to be $14.03 \%, 4.52 \%$ and $22.46 \%$ respectively. Optimzation and the use of bagasse ash gave a cost benefit of $9.24 \%$ with a better mix. The classical optimization technique appears to be suitable in soil stabilization.
\end{abstract}

Key words. Optimization, Cement, Bagasse Ash, Lateritic Soil, Compaction and Strength Characteristics

\section{INTRODUCTION}

Sugar-cane fiber obtained after squeezing out the sweet juice and when incinerated into ash yields bagasse ash. It has been found to be a good pozzolana globally and thus could serve as a supplement/partial replacement for cement in soil stabilization for lowcost roads $[1,2,3,4,5$ and so on]. The trade-off between cost effectiveness and the strength characteristics of the stabilized-soil matrix resulting from the partial replacement/supplement of cement with the bagasse ash for road work needs to be balanced. Because of limited resources, there is a need to be very conscious not to be wasteful. In other words, it would be beneficial to predict the optimum amount of bagasse ash required with a certain amount of cement in the stabilized-soil matrix to achieve the desired result with regards to the compaction and strength characteristics at minimum cost. Instead of going through a rigorous laboratory experiments with very many specimens in order to determine the optimum content of bagasse ash, geometric models developed could be used with relatively fewer laboratory observations to find an optimal solution.

Previously attempts had been made on optimization techniques for construction materials. Orthogonal method was used to identify the main influencing factors in mix ratio on compressive strength of concrete Portland cement, fly ash [6]. It was based upon a set of tests relating composition and engineering properties of concrete that optimal mix ratios for compressive strength of both 7 and 28 days were achieved. The optimization technique most commonly used for construction materials was the Sheffe's optimization regression method in simplex design [7]. Scheffe's and Tukey's methods were compared and the later was preferred when only pair wise comparisons were of interest because it gives a narrower confidence level while in general case the

\footnotetext{
* Corresponding author Tel: +234-703-399-3341
} 
first was preferred when many or all contrast might be of interest because it tends to give narrower confidence limit[8]. Researchers have widely used Scheffe's method in the past for optimization of construction materials. It was applied for the prediction of the compressive strength of aluminium waste-cement concrete and found that the compressive strength results predicted by the model conformed with the corresponding experimentally obtained values [9]. The method was also applied[10] to optimize the compressive strength of river stone aggregate concrete and the model was found to be adequate for predicting concrete mix ratios, when the desired compressive strength was known and vice versa. The method was used to optimize as well as predicting the compressive strength of recycled aggregate concrete which were in good agreement with their corresponding experimentally observed values[11].The method was also used [12] for prediction and optimization of compressive strength of sawdust ash-cement concrete. The results of the response function compared favourably with the corresponding experimental results. The optimum compressive strength of concrete at 28 days was found to be $20 \mathrm{~N} / \mathrm{mm}^{2}$ which corresponds to the mix ratio of 0.5: 0.95: 0.05: 2.25: 4 for water, cement, sawdust ash, sand and granites respectively.

However the Scheffe's simplex design [7] has some disadvantages associated with it. It stipulates that materials involved in the mix must be in volume but in soil stabilization volume batching is not usually recommended because soils are prone to variations in volume with time as a result of consolidation of the soils with time caused by natural and applied forces. Another major disadvantage was its rigidity in application. This was because it involves predetermined points or mix ratios obtained from a simplex mix design which makes it not to be amenable to stabilized soils. It was difficult to predict results of stabilized soils prior to adequate laboratory experiments because soils have peculiarities of structure. It was pointed out that peculiarities of structure may play more important role in cement stabilization than Atterberg limits. For example lateritic soils with the same and similar plasticity index may have completely different behaviours at mixing operation [13]. Consequently, the classical optimization has edge over the Scheffe's simplex regression method because it can use as many points as possible in formulating equations while the later uses limited number of points in formulating the optimization model which was considered to be grossly inadequate to match the complexity of soil stabilization. Even if the degree of the polynomial is raised in order to increase the number of points required, the short-coming in the model could be more compounded. Attempt had been made to verify the accuracy of Scheffe's third degree over the second degree polynomials and the difference was not very significant [14]. The Scheffe's simplex regression method might be useful in optimization in concrete mix because concrete is mostly made of coarse materials which are almost inert in reaction with cement. However soil stabilization of this nature was more complex in that the minerals present in the soil and the bagasse ash were all involved in the reaction with cement because they were pozzolanic in nature. Another advantage of the classical optimization over the Scheffe's simplex regression method was that it can handle or consider all the properties involved at the same time to predict a more reliable optimum point unlike the later which can only handle one property at a time for formulating optimization models. Thus for roadwork that requires more than one property for judgment, the classical optimization would be preferable.

Optimization is best achieved by the use of predictive models, thus, this work adopted geometric models developed from multiple regression on results obtained from the tests as shown in Tables 3 through 5 which covered relationships between the constituents, compaction and strength characteristics of the stabilized-soil matrix [15].Cost was attached to bagasse ash and presented in Table 1 which was used for formulating the model.

The following geometric models were developed:

$Z=10^{-8.73} M^{5.71} C^{0.203} H^{0.824} E^{-1.64}$

$H=10^{0.103} M^{1.59} C^{0.0590} E^{0747}$.

$E=10^{0.027} M^{-1.88} C^{0.0697} H^{1.06}$

$X=2.8 E+0.4 Z+0.055 M+20$

$Z$ is the Cost of bagasse ash in Kobo, $M$ is the optimum moisture content in percentage, $C$ is the california bearing ratio in percentage, $H$ is the unconfined compressive strength for 7 days curing period in $\mathrm{KN} / \mathrm{m}^{2}, E$ is the cement content in percentage, $X$ is the cost of stabilizing 100 grams of soil in kobo.

Table 1: Bagasse Ash Content and the Corresponding Attached Cost [source [5]]

\begin{tabular}{|l|l|l|l|l|l|l|l|l|l|l|l|}
\hline Bagasse Ash Content (\%) & 0 & 2 & 4 & 6 & 8 & 10 & 12 & 14 & 16 & 18 & 20 \\
\hline Cost (kobo) & 0 & 0.8 & 1.6 & 2.4 & 3.2 & 4.0 & 4.8 & 5.6 & 6.4 & 7.2 & 8.0 \\
\hline
\end{tabular}




\section{MATERIALS AND METHODS}

The soil samples used in this study were collected from a lateritic soil deposit in Oboro, Ikwuano Local Government Area of Abia State in Nigeria. It was collected at a depth of not less than $150 \mathrm{~mm}$ at 15 different points of about $3 \mathrm{~m}$ apart using the method of disturbed sampling technique and was air-dried. The bagasse residue was collected from Panyam district, Mangu Local Government Area, Plateau State of Nigeria. It was incinerated into ash in a furnace with temperature of up to $500^{\circ} \mathrm{C}$ for about 2 hours after which it was allowed to cool and thoroughly ground. It was then sieved through $75 \mu \mathrm{m}$ sieve as required by [16]. The test specimens were prepared by first thoroughly mixing dry quantities of pulverized soil with bagasse ash and Portland cement in a mixing tray to obtain a uniform mix. Constant cement contents of $2 \%, 4 \%, 6 \%$ and $8 \%$ with variations of bagasse ash from $0 \%$ to $20 \%$ at $2 \%$ intervals and all percentages used were by the weight of dry soil. The required amount of water which was determined from moisture- density relationships for stabilized-soil mixtures was then added to the mixture. The Standard Proctor mould was used for the compaction test in which 3 layers and 27 blows were given onto each layer with $2.5 \mathrm{Kg}$ rammer. The specimens from the Proctor mould were used as the unconfined compressive strength specimen and a correction factor of 1.04 was used on the results to conform to cylindrical specimens with a height/diameter ratio of 2:1 or $150 \mathrm{~mm}$ cube specimens. The membrane curing and 7 days curing period were used for the test specimens. The California Bearing Ratio was modified so as to conform to the recommendation of [17] which stipulates that the specimens should be cured for 6 days unsoaked, immersed in water for 24 hours and allowed to drain for 15 minutes before testing.

\section{FORMULATION OF MODEL}

Objective function was the function of which the optimal value (Maximum or minimum) is to be determined, subject to set of stated restrictions, or constraints placed on the variables concerned [18]. A non-linear programming model was developed where Equation (1) stood as the objective function because cost of bagasse ash content was the target function while Equations (2) and (3) with other single points form the constraints subject to the standards for stabilized materials for road-work. The established evaluation criterion for stabilized materials as
California Bearing Ratio of $180 \%$ for laboratory $\operatorname{mix}[17]$ and conventionally, the minimum values of Unconfined Compressive Strength at 7 days for cement stabilized soils were 750-1500, 1500-3000, 3000-6000 KN/m² for sub-base, base (lightly trafficked roads) and base (heavily trafficked roads) respectively. In addition, this study would only be meaningful provided that the cement content required does exceed that which was just satisfactory for economic application.

\subsection{Solution of Non-Linear Programming Model}

It was evident that the models would be non-linear because the results were non-linear. The model was linearized and solved with the simplex method. The first step was to ensure that each constraint was written with a positive right-hand side constant term. Then the inequalities were all expressed as equations by the introduction of slack variables.

\section{Example:}

$\mathrm{a} x+\mathrm{bY} \leq \mathrm{N}_{1}$ could be written as:

$\mathrm{a} x+\mathrm{bY}+\mathrm{W}_{1}=\mathrm{N}_{1}$

$c x+\mathrm{dY} \leq \mathrm{N}_{2}$ could be written as:

$c x+d Y+W_{2}=\mathrm{N}_{2}$

where a,b,c and d were coefficients; $x$ and $\mathrm{Y}$ were the problem variables; $\mathrm{N}_{1}$ and $\mathrm{N}_{2}$ were numerical values; and $W_{1}$ and $W_{2}$ were positive (or zero) variables with unit coefficients, required to make up the left-hand side to the value of the right hand side constant term. The new variables, $\mathrm{W}_{1}$ and $\mathrm{W}_{2}$ were regarded as slack variables. Subsequently, the simplex table (frame work) was formed as shown in Table 2 and the coefficients of the problem variables and of the slack variables in the constraints, together with the righthand side (RHS) numerical values in the column headed RHS. The Check column was included to ensure that the numerical calculations were correct for each row as the simplex operation took place. For each row, the sum of the entries in that row, including the RHS column were used to confirm the check column. It was always necessary that the columns of the slack variables form a unity matrix.

Table 2: Simplex Table Frame-Work

\begin{tabular}{|l|l|l|l|l|l|}
\hline$x$ & $\mathrm{Y}$ & $\mathrm{W}_{1}$ & $\mathrm{~W}_{2}$ & RHS & Check \\
\hline A & $\mathrm{B}$ & 1 & 0 & $\mathrm{~N}_{1}$ & Algebraic sum of row1 \\
\hline C & $\mathrm{D}$ & 0 & 1 & $\mathrm{~N}_{2}$ & Algebraic sum of row2 \\
\hline
\end{tabular}


The objective function was included in the bottom of table in a similar manner like the constraints and the row referred to as index row. In computing the simplex table, the following steps were taken:

i. The key column was selected as the column containing the highest negative entry in the index row.

ii. In each row, the values in the right-hand side column were divided by the corresponding positive entry in the key column; the row with the smallest ratio obtained became the key row while the number/entry at the intersection of the key column and key row became the key number or pivot number.

iii. All the entries in the key row were divided by the pivot number to reduce the pivot entry to unity while the rest of the entries in the table remain unchanged. The new version of the key row referred to as main row.

iv. The main row was used to operate on the remaining rows of the table including the index row to reduce the other entries in the key column to zero. It should be noted that the main row remains unaltered. The new value in any position in the other rows, including the right-hand side column and check column, were calculated as follows:

New number $=$ Old number - the product of the corresponding entries in the main row and key column.

v. The new values in the check column were confirmed that they were all equal to the sums of the entries in the corresponding rows otherwise it was an indication that there was an error somewhere.

vi. steps (i) to (v) were repeated until no negative entry remained in the index row.

\subsection{Sensitivity Analysis}

Sensitivity analysis would be very necessary to examine how dependable the linear programming model could be. These were performed by small adjustments of the right hand side of each of the constrained equations by $-5 \%,-2.5 \%,+2.5 \%$ and $+5 \%$ then allowing others to remain as they were. In each case the linear programming problem was solved to obtain the optimal solution in order to monitor the effects on it. In addition for purely local roads with very low volume of traffic, lower values of the combination of California bearing ratio and unconfined compressive strength that would be suitable but not necessarily the standard could be adopted or alternatively a lower cement content could be selected to determine the resultant optimal solution or bagasse ash content required.

\section{PRESENTATION OF MODEL AND RESULTS}

The optimum moisture content and strength characteristics were presented as follows in Tables 3 through 5:

\begin{tabular}{lcccc}
\multicolumn{4}{c}{ Table 3: Variations of Optimum Moisture Content with } \\
Increase in Bagasse Ash Content (BAC) at 2\%, 4\%, 6\% \\
and 8\% Cement Contents \\
BAC & \multicolumn{4}{c}{ Optimum Moisture Content (\%) } \\
\cline { 2 - 5 }$(\%)$ & $2 \%$ & $4 \%$ & $6 \%$ & $8 \%$ \\
& Cement & Cement & Cement & Cement \\
\hline 0 & 16.50 & 17.90 & 18.24 & 20.39 \\
2 & 16.80 & 17.97 & 18.41 & 20.56 \\
4 & 17.71 & 18.30 & 18.91 & 21.24 \\
6 & 18.74 & 19.69 & 20.85 & 21.63 \\
8 & 19.58 & 20.48 & 21.66 & 22.08 \\
10 & 20.23 & 21.29 & 22.39 & 22.63 \\
12 & 20.81 & 21.71 & 22.71 & 23.05 \\
14 & 21.32 & 22.17 & 23.29 & 23.95 \\
16 & 22.01 & 22.85 & 23.75 & 24.69 \\
18 & 22.22 & 23.21 & 24.23 & 25.02 \\
20 & 22.62 & 23.54 & 24.44 & 25.31 \\
\hline
\end{tabular}

Table 4: Variations of California Bearing Ratio with Increase Bagasse Ash Content at 2\%, 4\%, 6\% and 8\% Cement Contents

\begin{tabular}{lcccc}
\hline \multirow{2}{*}{$\begin{array}{c}\text { BAC } \\
(\%)\end{array}$} & \multicolumn{4}{c}{ California Bearing Ratio (\%) } \\
\cline { 2 - 5 } & $\begin{array}{c}2 \% \\
\text { Cement }\end{array}$ & $\begin{array}{c}4 \% \\
\text { Cement }\end{array}$ & $\begin{array}{c}6 \% \\
\text { Cement }\end{array}$ & $\begin{array}{c}8 \% \\
\text { Cement }\end{array}$ \\
\hline 0 & 22.30 & 57.99 & 83.34 & 147.16 \\
2 & 23.57 & 84.44 & 93.70 & 175.12 \\
4 & 25.42 & 85.20 & 104.94 & 196.37 \\
6 & 26.48 & 93.04 & 117.07 & 209.09 \\
8 & 25.13 & 109.13 & 123.68 & 221.03 \\
10 & 25.11 & 121.03 & 135.59 & 230.24 \\
12 & 24.98 & 135.19 & 176.12 & 242.05 \\
14 & 24.92 & 152.10 & 196.50 & 251.31 \\
16 & 24.70 & 163.59 & 207.26 & 265.30 \\
18 & 24.31 & 161.38 & 220.08 & 271.80 \\
20 & 24.23 & 160.96 & 239.16 & 276.30 \\
\hline
\end{tabular}

The non-linear programming model was formed as discussed in Section 3.0 which was linearized and solved with Simplex method (Section 3.1). The results of solution were presented as follows: 
Table 5: Variations of Unconfined Compressive Strength at 7 days with Increase in Bagasse Ash Content at 2\%,

$4 \%, 6 \%$ and $8 \%$ Cement Contents

\begin{tabular}{lllcl}
\hline \multirow{4}{*}{$\begin{array}{c}\text { BAC } \\
(\%)\end{array}$} & \multicolumn{4}{c}{ Unconfined Compressive Strength $\left(\mathrm{KN} / \mathrm{m}^{2}\right)$ at 7} \\
\cline { 2 - 5 } & $2 \%$ Cement & $4 \%$ Cement & $\begin{array}{c}6 \% \\
\text { Cement }\end{array}$ & $\begin{array}{c}8 \% \\
\text { Cement }\end{array}$ \\
\hline 0 & 213 & 419 & 549 & 942 \\
2 & 228 & 454 & 642 & 998 \\
4 & 248 & 492 & 683 & 1049 \\
6 & 273 & 534 & 801 & 1087 \\
8 & 292 & 575 & 854 & 1132 \\
10 & 308 & 613 & 907 & 1180 \\
12 & 321 & 642 & 941 & 1221 \\
14 & 335 & 665 & 985 & 1298 \\
16 & 349 & 697 & 1018 & 1366 \\
18 & 353 & 717 & 1057 & 1396 \\
20 & 364 & 733 & 1073 & 1424 \\
\hline
\end{tabular}

\subsection{Non-linear Programming Model}

The geometric models could be used to form the nonlinear programming model as shown

Minimize:

$Z=10^{-8.73} M^{5.71} C^{0.203} H^{0.824} E^{-1.64}$

Subject to:

$10^{0.103} M^{1.59} C^{0.059} E^{0.747} \geq 750$

$C \geq 180$

$10^{0.027} M^{-1.88} C^{0.0697} H^{1.06} \leq 5$

$C \leq 190$

$M \leq 23.5$

$H \leq 760$

Linearize the model

$$
\begin{array}{r}
\log Z=-8.73 \log 10+5.71 \log M-1.64 \log E \\
+0.203 \log C+0.824 \log H
\end{array}
$$

Subject to:

$$
\begin{gathered}
0.103 \log 10+1.59 \log M+0.0590 \log C+0.747 \log E \\
\geq \log 750 \\
\log C \geq \log 180 \\
0.027 \log 10-1.88 \log M+0.0697 \log C+1.06 \log H \\
\leq \log 5 \\
\log C \leq \log 190 \\
\log M \leq \log 23.5 \\
\log H \leq \log 760
\end{gathered}
$$

Let:

$\log Z=Q ; \log M=R ; \log E=U ; \log C=V ;$

$\log H=T$

Thus the model becomes;

$$
Q=-8.73+5.71 R-1.64 U+0.203 \mathrm{~V}+0.824 T
$$

Subjected to:

$$
\begin{gathered}
0.103+1.59 R+0.0590 V+0.747 U \geq 2.875061 \\
V \geq 2.255273 \\
0.027-1.88 R+0.0697 V+1.06 T \leq 0.698970 \\
V \leq 2.278754 \\
R \leq 1.371068 \\
T \leq 2.880814
\end{gathered}
$$

Standard form

$$
\begin{gathered}
Q-5.71 R+1.64 U-0.203 V-0.824 T=-8.73 \\
1.59 R+0.0590 V+0.747 U-W_{1}+W_{2}=2.772061
\end{gathered}
$$$$
V-W_{3}+W_{4}=2.255273
$$$$
-1.88 R+0.0697 V+1.06 T+W_{5}=0.671970
$$

$V+W_{6}=2.278754$

$R+W_{7}=1.371068$

$T+W_{8}=2.880814$

Putting in matrix form and solving with Simplex method

Table 6:First Simplex Matrix

\begin{tabular}{cccccccc}
\hline Basic & $W_{2}$ & $W_{4}$ & $W_{5}$ & $W_{6}$ & $W_{7}$ & $W_{8}$ & $Q$ \\
\hline$R$ & 1.59 & 0 & $-1.88^{*}$ & 0 & 1 & 0 & -5.71 \\
$V$ & 0.0590 & 1 & 0.0697 & 1 & 0 & 0 & -0.203 \\
$U$ & 0.747 & 0 & 0 & 0 & 0 & 0 & 1.64 \\
$T$ & 0 & 0 & 1.06 & 0 & 0 & 1 & -0.824 \\
$W_{1}$ & -1 & 0 & 0 & 0 & 0 & 0 & 0 \\
$W_{2}$ & 1 & 0 & 0 & 0 & 0 & 0 & $\mathrm{M}$ \\
$W_{3}$ & 0 & -1 & 0 & 0 & 0 & 0 & 0 \\
$W_{4}$ & 0 & 1 & 0 & 0 & 0 & 0 & $\mathrm{M}$ \\
$W_{5}$ & 0 & 0 & 1 & 0 & 0 & 0 & 0 \\
$W_{6}$ & 0 & 0 & 0 & 1 & 0 & 0 & 0 \\
$W_{7}$ & 0 & 0 & 0 & 0 & 1 & 0 & 0 \\
$W_{8}$ & 0 & 0 & 0 & 0 & 0 & 1 & -8.73 \\
RHS & 2.772061 & 2.255273 & 0.671970 & 2.278754 & 1.371068 & 2.880814 & $2 \mathrm{M}-13.827$ \\
Check & 5.168061 & 3.255273 & 0.921670 & 4.278754 & 3.371068 & 4.880814 & \\
\hline
\end{tabular}


Table 6 formed the first matrix of the Simplex iteration. The highest negative entry in the index line, ' $Q$ ' (objective function) in the side of the problem variables was -5.71 , thus, the right-hand side (RHS) line divided by each corresponding entry in the ${ }^{\prime} R^{\prime}$ line of which the line ' $W_{5}$ 'gave the least ratio. Therefore, 1.88 became the pivot number. Then all the entries in line ' $W_{5}$ ' divided by the pivot number to reduce the pivot number to unity. In the exception of line ${ }^{\prime} W_{5}^{\prime}$, all the other entries were operated on by subtracting the product of the corresponding entries in lines ' $W_{5}$ ' and ' $R$ ' for each entry from the old entries which gave new entries that resulted in the Simplex matrix in Table 7. Thus ' $W_{5}$ ' became equal to' $R^{\prime}$. In order to ensure accuracy, each of the entries in the 'check' line was confirmed to be equal to the sum of all the corresponding entries in the same line.
Table 7 formed the first matrix of the Simplex iteration. The highest negative entry in the index line, ' $Q$ ' (objective function) in the side of the problem variables was-4.043469, thus, the right-hand side (RHS) line divided by each corresponding entry in the ' $T$ ' line of whichthe line ' $W$ s'gave the least ratio. Therefore, -4.043469 became the pivot number. Then all the entries in line ' $W_{8}$ ' divided by the pivot number to reduce the pivot number to unity. In the exception of line ' $W_{8}$ ', all the other entries were operated on by subtracting the product of the corresponding entries in lines ' $W_{8}$ ' and ' $T$ ' for each entry from the old entries which gave new entries that resulted in the Simplex matrix in Table 8 . Thus ' $W_{8}$ ' became equal to ' $T$ '. In order to ensure accuracy, each of the entries in the 'check' line was confirmed to be equal to the sum of all the corresponding entries in the same line.

Table 7: First Simplex Iteration

\begin{tabular}{|c|c|c|c|c|c|c|c|}
\hline Basic & $W_{2}$ & $W_{4}$ & $R$ & $W_{6}$ & $W_{7}$ & $W_{8}$ & $Q$ \\
\hline$R$ & 0 & 0 & 1 & 0 & 0 & 0 & 0 \\
\hline$V$ & 0.117949 & 1 & -0.037075 & 1 & 0.037075 & 0 & -0.414698 \\
\hline$U$ & 0.747 & 0 & 0 & 0 & 0 & 0 & 1.64 \\
\hline$T$ & 0.896490 & 0 & -0.563830 & 0 & 0.563830 & $1^{*}$ & -4.043469 \\
\hline$W_{1}$ & -1 & 0 & 0 & 0 & 0 & 0 & 0 \\
\hline$W_{2}$ & 1 & 0 & 0 & 0 & 0 & 0 & M \\
\hline$W_{3}$ & 0 & -1 & 0 & 0 & 0 & 0 & 0 \\
\hline$W_{4}$ & 0 & 1 & 0 & 0 & 0 & 0 & M \\
\hline$W_{5}$ & 0.845745 & 0 & -0.531915 & 0 & 0.531915 & 0 & -3.037235 \\
\hline$W_{6}$ & 0 & 0 & 0 & 1 & 0 & 0 & 0 \\
\hline$W_{7}$ & 0 & 0 & 0 & 0 & 1 & 0 & 0 \\
\hline$W_{8}$ & 0 & 0 & 0 & 0 & 0 & 1 & 0 \\
\hline RHS & 3.340396 & 2.255273 & -0.357431 & 2.278754 & 1.728499 & 2.880814 & -10.770931 \\
\hline Check & 5.947559 & 3.255273 & -0.490250 & 4.278754 & 3.861318 & 4.880814 & $2 M-16.626328$ \\
\hline
\end{tabular}

The * shows the pivot number

Table 8: Second Simplex Iteration

\begin{tabular}{|c|c|c|c|c|c|c|c|}
\hline Basic & $W_{2}$ & $W_{4}$ & $R$ & $W_{6}$ & $W_{7}$ & $T$ & $Q$ \\
\hline$R$ & 0 & 0 & 1 & 0 & 0 & 0 & 0 \\
\hline$V$ & 0.117949 & $1^{*}$ & -0.037075 & 1 & 0.037075 & 0 & -0.414698 \\
\hline$U$ & 0.747 & 0 & 0 & 0 & 0 & 0 & 1.64 \\
\hline$T$ & 0 & 0 & 0 & 0 & 0 & 1 & 0 \\
\hline$W_{1}$ & -1 & 0 & 0 & 0 & 0 & 0 & 0 \\
\hline$W_{2}$ & 1 & 0 & 0 & 0 & 0 & 0 & M \\
\hline$W_{3}$ & 0 & -1 & 0 & 0 & 0 & 0 & 0 \\
\hline$W_{4}$ & 0 & 1 & 0 & 0 & 0 & 0 & M \\
\hline$W_{5}$ & 0.845745 & 0 & -0.531915 & 0 & 0.531915 & 0 & -3.037235 \\
\hline$W_{6}$ & 0 & 0 & 0 & 1 & 0 & 0 & 0 \\
\hline$W_{7}$ & 0 & 0 & 0 & 0 & 1 & 0 & 0 \\
\hline$W_{8}$ & -0.896490 & 0 & 0.563830 & 0 & -0.563830 & 1 & 4.043469 \\
\hline RHS & 0.757775 & 2.255273 & 1.266858 & 2.278754 & 0.104210 & 2.880814 & 0.877551 \\
\hline Check & 1.571958 & 3.255273 & 2.261699 & 4.278754 & 1.109369 & 4.880814 & $2 \mathrm{M}+3.109092$ \\
\hline
\end{tabular}

The * shows the pivot number 
Table 8 formed the second matrix of the Simplex iteration. The highest negative entry in the index line, ' $Q$ ' (objective function) in the side of the problem variables was-0.414698, thus, the right-hand side (RHS) line divided by each corresponding entry in the ' $V$ ' line of which the line ' $W_{4}$ 'gave the least ratio. Therefore, -0.414698 became the pivot number. Then all the entries in line ' $W_{4}$ ' divided by the pivot number to reduce the pivot number to unity. In the exception of line ' $W_{4}$ ', all the other entries were operated on by subtracting the product of the corresponding entries in lines ' $W_{4}$ ' and ' $V$ ' for each entry from the old entries which gave new entries that resulted in the Simplex matrix in Table 9. Thus ' $W_{4}$ ' became equal to ' $V$ '. In order to ensure accuracy, each of the entries in the 'check' line was confirmed to be equal to the sum of all the corresponding entries in the same line.

Table 9 formed the third matrix of the Simplex iteration. There is no longer any negative entry in the index line, ' $Q$ ' (objective function) in the side of the problem variables but' $W_{2}$, , $W_{6}$ ' and' $W_{7}$ ' in the 'basic' - ' $Q$ ' line were needed to be replaced by any of' ' $U^{\prime}$, ' $W_{1}{ }^{\prime}$ or $^{\prime} W_{3}{ }^{\prime}$ because ${ }^{\prime} U^{\prime},{ }^{\prime} W_{1}$ ' or ' $W_{3}$ ' were not in that line in the first Simplex matrix (see Table 6) thus 1.64 was selected, the right-hand side (RHS) line divided by each corresponding entry in the ' $U^{\prime}$ line of which line ' $W_{2}$ 'gave the least ratio. Therefore, 0.747 became the pivot number. Then all the entries in line ' $W_{2}{ }^{\prime}$ divide by the pivot number to reduce the pivot number to unity. In the exception of line ' $W_{2}$ ', all the other entries were operated on by subtracting the product of the corresponding entries in lines ' $W_{2}$ ' and ' $U$ ' for each entry from the old entries which gave new entries that resulted in the Simplex matrix in Table 10. Thus ' $W_{2}$ ' became equal to ' $U$ '. In order to ensure accuracy, each of the entries in the 'check' line was confirmed to be equal to the sum of all the corresponding entries in the same line.

Table 9: Third Simplex Iteration

\begin{tabular}{cccccccc}
\hline Basic & $W_{2}$ & $V$ & $R$ & $W_{6}$ & $W_{7}$ & $T$ & $Q$ \\
\hline$R$ & 0 & 0 & 1 & 0 & 0 & 0 & 0 \\
$V$ & 0 & 1 & 0 & 0 & 0 & 0 & 0 \\
$U$ & $0.747^{*}$ & 0 & 0 & 0 & 0 & 0 & 1.64 \\
$T$ & 0 & 0 & 0 & 0 & 0 & 1 & 0 \\
$W_{1}$ & -1 & 0 & 0 & 0 & 0 & 0 & 0 \\
$W_{2}$ & 1 & 0 & 0 & 0 & 0 & 0 & $\mathrm{M}$ \\
$W_{3}$ & 0.117949 & -1 & -0.037075 & 1 & 0.037075 & 0 & -0.414698 \\
$W_{4}$ & -0.117949 & 1 & 0.037075 & -1 & -0.037075 & 0 & $\mathrm{M}+0.414698$ \\
$W_{5}$ & 0.845745 & 0 & -0.531915 & 0 & 0.531915 & 0 & -3.037235 \\
$W_{6}$ & 0 & 0 & 0 & 1 & 0 & 0 & 0 \\
$W_{7}$ & 0 & 0 & 0 & 0 & 1 & 0 & 0 \\
$W_{8}$ & -0.896490 & 0 & 0.563830 & 0 & -0.563830 & 1 & 4.043469 \\
RHS & 0.491768 & 2.255273 & 1.350472 & 0.023481 & 0.020596 & 2.880814 & 1.812808 \\
Check & 1.188002 & 3.255273 & 2.382388 & 1.023481 & 0.988680 & 4.880814 & $2 \mathrm{M}+4.459047$ \\
\hline
\end{tabular}

The * shows the pivot number

Table 10: Fourth Simpex Iteration

\begin{tabular}{cccccccc}
\hline Basic & $U$ & $V$ & $R$ & $W_{6}$ & $W_{7}$ & $T$ & $Q$ \\
\hline$R$ & 0 & 0 & 1 & 0 & 0 & 0 & 0 \\
$V$ & 0 & 1 & 0 & 0 & 0 & 0 & 0 \\
$U$ & 1 & 0 & 0 & 0 & 0 & 0 & 0 \\
$T$ & 0 & 0 & 0 & 0 & 0 & 1 & 0 \\
$W_{1}$ & -1.338688 & 0 & 0 & 0 & 0 & 0 & 2.195448 \\
$W_{2}$ & 1.338688 & 0 & 0 & 0 & 0 & 0 & $\mathrm{M}-2.195448$ \\
$W_{3}$ & 0.157897 & -1 & -0.037075 & $1 *$ & 0.037075 & 0 & -0.673649 \\
$W_{4}$ & -0.157897 & 1 & 0.037075 & -1 & -0.037075 & 0 & $\mathrm{M}+0.673649$ \\
$W_{5}$ & 1.132189 & 0 & -0.531915 & 0 & 0.531915 & 0 & -4.894025 \\
$W_{6}$ & 0 & 0 & 0 & 1 & 0 & 0 & 0 \\
$W_{7}$ & 0 & 0 & 0 & 0 & 1 & 0 & 0 \\
$W_{8}$ & -1.200121 & 0 & 0.563830 & 0 & -0.563830 & 1 & 6.011667 \\
RHS & 0.658324 & 2.255273 & 1.350472 & 0.023481 & 0.020596 & 2.880814 & 0.733157 \\
Check & 1.590364 & 3.255273 & 2.382388 & 1.023481 & 0.988680 & 4.880814 & $2 \mathrm{M}+1.850850$ \\
\hline
\end{tabular}

The * shows the pivot number 
Table 10 formed the fourth matrix of the Simplex iteration. There is no longer any negative entry in the index line, ' $Q$ ' (objective function) in the side of the problem variables. Infact, all the entries had been reduced to zero (0) but ' $W_{6}$ ' and' $W_{7}$ ' in the 'basic' - ' $Q$ ' line were needed to be replaced by any of ' $W_{1}{ }^{\prime}$ or' $^{\prime} W_{3}$ 'because' $W_{1}$ ' or ' $W_{3}$ ' were not in that line in the first Simplex matrix (see Table 6). However ' $W_{1}$ 'had no corresponding value (o) for ' $W_{6}^{\prime}$ and $W_{7}$ ' thus0.673649 was selected for line ' $W_{3}{ }^{\prime}$, the right-hand side (RHS) line divided by each corresponding entry in line' $W_{3}$ ' of which line ' $W_{6}$ 'gave the least ratio. Therefore, 1became the pivot number then the pivot number was already unity. In the exception of line ' $W_{3}$ ',all the other entries were operated on by subtracting the product of the corresponding entries in lines ' $W_{3}$ ' and ' $W_{6}$ ' for each entry from the old entries which gave new entries that resulted in the Simplex matrix in Table 11 . Thus ' $W_{3}$ ' became equal to ${ }^{\prime} W_{6}{ }^{\prime}$ In order to ensure accuracy, each of the entries in the 'check' line was confirmed to be equal to the sum of all the corresponding entries in the same line.

Table 11 formed the fifth matrix of the Simplex iteration. There is no longer any negative entry in the index line, ' $Q$ ' (objective function) in the side of the problem variables. Infact, all the entries had been reduced to zero (0) but ' $W_{7}$ ' in the 'basic' - ' $Q$ ' line would be needed to be replaced by ${ }^{\prime} W_{1}$ ' because ' $W_{1}$ ' was not in that line in the first Simplex matrix (see Table 6). However ' $W_{1}$ ' had no corresponding value (o) for ' $W_{6}$ ' and' $W_{7}$ ' thus, no further iteration could take place. In order to ensure accuracy, each of the entries in the 'check' line was confirmed to be equal to the sum of all the corresponding entries in the same line. The optimal values obtained after the first through the fifth iterations which were the entries in the right-hand side (RHS) line in Table 11 and were given below;

Thus at optimal solution,

$$
\begin{gathered}
U=0.654616 ; V=2.278754 ; R=1.351343 ; \\
T=2.880814 ; Q=0.748975
\end{gathered}
$$

In other words;

$$
\begin{aligned}
& \log E=U ; \log C=V ; E=10^{0.654616}=4.51457 \% \\
& C=102.278754=190 \%, \quad \log M=1.351343 ; \\
& \log H=T ; M=10^{1.351343}=22.456548 \% ; \\
& \quad H=10^{2.880814}=760 \mathrm{KN} / \mathrm{m}^{2} ; \log Z=Q ; \\
& \quad Z=10^{0.748975}=5.610157 \\
& Z=\frac{5.610157}{0.4}=14.025392 \% \text { (see Table } 1,2 \% \text { bagasse } \\
& \text { ash }=0.8 \text { kobo) } \\
& \text { Using Equation (4) to determine the cost of stabilizing }
\end{aligned}
$$
100 grams of soil with this mix

$X=2.8(4.52)+0.4(14.03)+0.055(22.46)+20=$ 39.50 Kobo

Considering stabilizing the soil with only cement (without bagasse ash) for unoptimized condition

$X=2.8(8)+0.4(0)+0.055(20.39)+20=$

43.52 Kobo

It was evident that the cost of the foregoing mix (43.52 kobo) for stabilizing 100 grams of soil would be significantly more expensive than the cost of stabilizing with the optimal solution (39.50 kobo) about $9.24 \%$ gain in cost. In the long run when much weight of the soil would be required for road construction work, it had clearly shown the cost

\begin{tabular}{|c|c|c|c|c|c|c|c|}
\hline Basic & $U$ & V & $R$ & $W_{3}$ & $W_{7}$ & $T$ & $Q$ \\
\hline$R$ & 0 & 0 & 1 & 0 & 0 & 0 & 0 \\
\hline V & 0 & 1 & 0 & 0 & 0 & 0 & 0 \\
\hline$U$ & 1 & 0 & 0 & 0 & 0 & 0 & 0 \\
\hline$T$ & 0 & 0 & 0 & 0 & 0 & 1 & 0 \\
\hline$W_{1}$ & -1.338688 & 0 & 0 & 0 & 0 & 0 & 2.195448 \\
\hline$W_{2}$ & 1.338688 & 0 & 0 & 0 & 0 & 0 & M- 2.195448 \\
\hline$W_{3}$ & 0 & 0 & 0 & 1 & 0 & 0 & 0 \\
\hline$W_{4}$ & 0 & 0 & 0 & -1 & 0 & 0 & M \\
\hline$W_{5}$ & 1.132189 & 0 & -0.531915 & 0 & 0.531915 & 0 & -4.894025 \\
\hline$W_{6}$ & -0.157897 & 1 & 0.037075 & 1 & -0.037075 & 0 & 0.673649 \\
\hline$W_{7}$ & 0 & 0 & 0 & 0 & 1 & 0 & 0 \\
\hline$W_{8}$ & -1.200121 & 0 & 0.563830 & 0 & -0.563830 & 1 & 6.011667 \\
\hline RHS & 0.654616 & 2.278754 & 1.351343 & 0.023481 & 0.019725 & 2.880814 & 0.748975 \\
\hline Check & 1.428759 & 4.278754 & 2.420334 & 1.023481 & 0.950734 & 4.880814 & $2 \mathrm{M}+2.540317$ \\
\hline
\end{tabular}
benefit of using bagasse ash as admixture. Besides, at $8 \%$ cement content with no bagasse ash, the California bearing ratio was $147.16 \%$ which fell short of the $180 \%$ California bearing ratio value as stipulated by the Nigeria General Specification of Road works and Bridges [17] though it had strength of $942 \mathrm{KN} / \mathrm{m}^{2}$ but the optimal solution had satisfactory values for the evaluation criterions.

Table 11: Fifth Simplex Iteration 
Table 12: Change in Optimal Solution with Small Changes in Constrained Equations

\begin{tabular}{l|ccccc}
\hline \multirow{2}{*}{$\begin{array}{l}\text { Enstrained } \\
6\end{array}$} & \multicolumn{5}{|c}{ \% Change in Optimal Solution } \\
\cline { 2 - 6 } & $-2.5 \%$ & $-5 \%$ & $0 \%$ & $+2.5 \%$ & $+5 \%$ \\
& Adjustment & Adjustment & Adjustment & Adjustment & Adjustment \\
\cline { 2 - 6 } 7 & 5.70 & 11.90 & 0 & -5.42 & -10.12 \\
8 & 0 & 0 & 0 & 0 & 0 \\
9 & 13.19 & 28.51 & 0 & -11.40 & -21.24 \\
10 & -1.71 & -3.42 & 0 & 1.64 & 3.35 \\
11 & 0 & 0 & 0 & 0 & 0 \\
\hline
\end{tabular}

\subsection{Results of Sensitivity Analysis on Constrained Equations}

Small changes of $-2.5 \%,-5 \%, 0 \%,+2.5 \%$ and $+5 \%$ in the right-hand side of the Constrained Equations were considered which were executed in the same way by formulation of the Simplex matrix after which the iterations were carried out as in Tables 6 through 11 and the results of the corresponding changes in optimal solution in percentages were presented in Table 12. The optimal solution increased with small decrease in the right hand side of Constrained Equations 6 and 8 and vice versa while the optimal solution increased with small increments in the right hand side Constrained Equations 9 and 11 which implied that the four of them were sensitive with Constrained Equation 11 being the most sensitive. Constrained Equation 8 which was responsible for cement content could be very useful in adjusting the cement content whereas the other three could also be used in adjusting the strength characteristics as desired especially for purely local roads with very low volume of traffic which has lower strength requirements. There were virtually no changes in optimal solution with small changes in the right hand side of Constrained Equations 7 and 10 which were single point constraint Equations of California bearing ratio and optimum moisture content respectively implied that both appeared to be insensitive. However, it was still very necessary not to relax them because they were very relevant in ensuring that the linear programming model was solvable. Thus, the model contained four basic and two surplus variables which required at least six constrained equations to make it solvable.

\section{CONCLUSIONS}

After the optimization technique was carried out on the lateritic soil treated with cement and bagasse ash. The following conclusions were drawn:

i. The optimal values at the desired unconfined compressive strength and California bearing ratio for sub-base of road-work for bagasse ash content, cement content and optimum moisture content were $14.03 \%, 4.52 \%$ and $22.46 \%$ respectively.

ii. The classical optimization technique appeared to be suitable in soil stabilization because it allowed for adjusting the constituents and the strength characteristics as desired.

iii. Optimzation and the use of bagasse ash gave a cost benefit of $9.24 \%$ with a better mix ratio.

\section{ACKNOWLEDGEMENTS}

The authors sincerely wish to express profound gratitude to GEOTECHNICAL ENGINEERING SERVICES LIMITED, Calabar, Nigeria and her technical staff for their support during the laboratory work

\section{REFERENCES}

[1] Sadeeq, J. A., Ochepo, J. and Salahudeen, A. B. "Assessment of Bagasse Ash Effect on the California Bearig Ratio of Used oil contaminated Lateritic soils" Nigerian Journal of Technology, Vol. 34, Number 2, 2015, pp223-231.

[2] Osinubi, K. J., Bafyau, V. and Eberemu, A.O. "Bagasse Ash Stabilization of Lateritic Soil" Earth and Environmental Science Appropriate Technologies for Environmental Protection in Developing World, Book Chapter, Springer Link Science and Business Media, 2009, pp 271-280.

[3] Osinubi, K. J., Ijimdiya, T. S. and Nmadu, I. "Lime Stabilization of Black Cotton Soil Using Bagasse Ash as Admixture" Advanced Materials Research, Switzerland, Vol. 62-64, 2009, pp 3-10.

[4] Eberemu, A. 0. "Evaluation of Bagasse Ash Treated Lateritic Soil as a Potential Barrier Material in Waste Containment Application" ActaGeotechnica, Springer Publishers, Vol. 8, Number 4, 2013, pp 407-421.

[5] Okonkwo, U.N. and Agunwamba, J. C. "Characterization of Bagasse Ash and Lateritic Soil for Low-Cost Roads in Nigeria" Nigerian Journal of Soil and Environmental Research" Vol. 12, 2014, pp 154-159.

[6] Lixiaoyong, M. W. “Optimization for Mix Design of 
High-Performance Concrete Using Orthogonal Test" Innovation Computing and Information Communications in Computer and Information Science, Springer Publishers, 232, 2011 pp364-374.

[7] Scheffe, H. "Experiments with Mixtures" Journal of the Royal Statistical Society, Ser. B 20, 1958, pp344360.

[8] NIST/SEMATECH, Engineering Statistics, EHandbook. www.iel.nist.gov/dv898/handbook Accessed:2009.

[9] Arimanwa, J. I., Onwuka, D. O., Arimanwa, M.C. and Onwuka, U. S. (): "Prediction of the Compressive Strength of Aluminium Waste-Cement Concrete Using Scheffe's Theory" Journal of Materials in Civil Engineering, Vol. 24, Number 2, 2012, pp177-183.

[10] Ezeh, J. C. and Ibearugbulem, O. M. "Compressive Cube Strength of River Stone Aggregate Concrete" African Journals Online, Vol. 5, Number 4,2009, pp303-308.

[11] Ezeh, J. C. and Ibearugbulem, O. M." Optimization of Compressive Strength of Recycled Aggregate Concrete Using Scheffe's Second Degree Simplex Model" International Journal of Applied Engineering Research, Vol.5, Number 10,2010, pp1757-1764.

[12] Onwuka, D. O. Anyaogu, L.; Chijioke, C. and Okoye, P. C. Prediction and Optimization of Compressive
Strength of Sawdust Ash-Cement Concrete Using Scheffe's Simplex Design" International Journal of Scientific and Research Publications, Vol. 3, Number 5, 2013, pp1-7.

[13] Osinubi, K. J. "Influence of Compaction Delay on Properties of Cement-Stabilized Lateritic Soil" Nigerian Journal of Engineering, Vol. 6, Number 1, 1998, pp13-25.

[14] Obams, S. 0. "The Accuracy of Scheffe's Third Degree over the Second degree Optimization Regression Polynomials" Nigerian Journal of Technology, Vol. 25 Number 2, 2006, pp 5-15.

[15] Okonkwo, U. N., Optimization of Bagasse Ash Content in Cement- Stabilized Lateritic Soil, Unpublished Ph.D. Thesis Submitted to Department of Civil Engineering, University of Nigeria Nsukka, 2015.

[16] BS 12, Specification for Portland Cement, British Standard Institute, London, 1991.

[17] Nigerian General Specification, "Bridges and Roads works" Federal Ministry of Works, Abuja.Vol.11, 1997.

[18] Stroud, K. A., Further Engineering Mathematics, Third Edition, Macmillan Press Limited, London, United Kingdom, 1996. 